\title{
POLÍTICAS PÚBLICAS PARA O CAMPO E \\ DESENVOLVIMENTO RURAL SUSTENTÁVEL
}

\section{PUBLIC POLITICS FOR THE FIELD AND SUSTAINABLE RURAL DEVELOPMENT}

\begin{abstract}
Ananda de Carvalho Graduada em Geografia Lic. Plena e Mestranda em Geografia pela Universidade Federal de Santa Maria - anandadecarvalho10@yahoo.com.br. Cesar De David Prof. Dr. Adjunto do Depto. de Geociências da Universidade Federal de Santa Maria cdedavid2009@gmail.com.
\end{abstract}

\begin{abstract}
RESUMO
Este artigo tem como objetivo discutir as diferentes concepções em torno da questão do desenvolvimento e da sustentabilidade, estabelecendo relação com os princípios agroecológicos e as políticas públicas implantadas no espaço rural brasileiro na última década. Considerando a diversidade das contradições existentes no debate e na prática estatal, destacam-se possibilidades e dificuldades de estabelecer formas alternativas de desenvolvimento sustentável no campo. Todavia, constata-se a necessidade de transformações mais profundas na organização da sociedade, que alterem as relações de exploração entre os homens e as mulheres e contra a natureza. Por isso, as alternativas sustentáveis desenvolvidas no modelo atual de produção não estão completas, mas cumprem a função de enfrentar a hegemonia do capital.
\end{abstract}

Palavras - chave: desenvolvimento - sustentabilidade - espaço rural - agroecologia políticas públicas.

\begin{abstract}
This paper deals with a discussion about different conception related to development and sustainability, establishing a relation with the agro-ecological and public politics principals implanted in the Brazilian rural space in the last decade. Considering the diversity of existent contradictions both on the debate and on the state practice, this work highlights possibilities and difficulties of establishing alternative forms of sustainable development in the field. However, one found out that deeper changes are necessary in the society organization in a way that it alters the exploit relations between men and women as well as against the nature. In this way, the sustainable alternatives developed in the current model of production are not completed, but they accomplish the role of confronting the capital hegemony.
\end{abstract}

Key-words: development - sustainability - rural space - agroecology - public policy.

\section{Introdução}

Ao discutir-se o conceito de desenvolvimento sustentável é necessário prudência em virtude das distorções que o assunto sofre de acordo com os diferentes contextos 
históricos, interesses políticos e conjuntura econômica em que se acha inserido. Nesse sentido, considera-se que a questão que envolve as diferentes concepções de desenvolvimento sustentável ainda está longe de ser respondida e esclarecida, pois a sustentabilidade não é compreendida da mesma forma pelas instituições públicas, privadas, não governamentais, pelos movimentos sociais e intelectuais, o que tem causado problemas quando se deseja melhorar a vida das pessoas sem comprometer a natureza.

No caso das políticas públicas, nota-se que a atuação do Estado tem incorporado, em seu discurso, a necessidade da sustentabilidade. Trata-se, nesse sentido, de igualdade social e solidariedade, entretanto, não se interfere profundamente na concentração das riquezas, das terras e na exploração do trabalho, o que demarca as contradições da intenção de se produzir uma sociedade sustentável.

Nessa perspectiva, esse texto visa a destacar as distintas concepções de desenvolvimento e sustentabilidade, ressaltando a importância da agroecologia para a produção do espaço rural e as influências desse debate na elaboração das políticas e na gestão territorial. Entretanto, a agroecologia, entendida como estratégia, movimento e alternativa, que enfrenta o modelo hegemônico de desenvolvimento implantado no campo, assim como as políticas públicas, que são compreendidas como meio de mediar os conflitos entre as diferentes classes e interesses, são responsáveis por alguns avanços, que o são ainda repletos de contradição, parciais, pontuais e insuficientes no que tange às questões estruturais.

\section{A questão do desenvolvimento e a sustentabilidade}

Ao longo da história, a questão do desenvolvimento tem sido interpretada de diversas formas, de acordo com o contexto social, político e, sobretudo, econômico. Segundo Esteva (2000), o desenvolvimento sofreu uma inflação conceitual, porém, em geral, acaba associado ao crescimento, à evolução e à maturação, ou seja, tem sentido de mudança favorável.

Contudo, de forma dominante, o desenvolvimento vem sendo associado ao crescimento econômico. Para Esteva (2000), mesmo que diversos estudos comprovem que o crescimento econômico, por si só, não melhora as condições sociais, gerando pobreza e desigualdades, até hoje, o conceito de desenvolvimento encontra-se, de forma 
distorcida, articulado intimamente à economia. O senso comum, segundo o autor, já está impregnado pela maneira econômica de pensar, mesmo que os órgãos internacionais, os grupos sociais e os pesquisadores já tenham apontado a necessidade do “desenvolvimento” social. Isso porque, fundamentalmente, as estruturas de organização econômica e socioespacial, atualmente sustentadas pelas relações capitalistas de produção, não são alteradas.

É nesse sentido que conotações distorcidas do conceito são estabelecidas como lei. Um exemplo é a incorporação do conceito de subdesenvolvimento entre os diversos povos do mundo, concebido como um legado que necessita ser superado. Esteva (2000) denuncia a invenção do subdesenvolvimento, especialmente após a Segunda Guerra Mundial, como uma criação do Presidente Truman endereçada às Nações Unidas. Conforme o autor, a partir dessa construção distorcida do conceito, consolidou-se a colonização do "desenvolvimento" sobre o "subdesenvolvimento", isso sob a promessa de melhorias sociais de vida e enriquecimento. Desde então, as nações deixaram de olhar para si na busca por respostas externas que as levassem ao “desenvolvimento”.

Assim sendo, esse olhar sobre o desenvolvimento não resolveu os problemas sociais e, além disso, aprofundou as desigualdades e provocou fortes impactos à natureza. De acordo com esse modelo econômico, o trabalho e a natureza são, somente, mercadorias. Nesse contexto, a apropriação veloz dos recursos naturais, através do trabalho alienado, que busca, sobretudo, o lucro, é insustentável.

É por meio da consciência de que a exploração dos recursos naturais escassos não condiz com a satisfação das necessidades da população inventadas pelo modelo econômico consumista que se torna necessário rediscutir o desenvolvimento. Nesse cenário, surgem as discussões sobre o desenvolvimento sustentável e a necessidade de sustentabilidade entre as relações de produção. São ideias que, inicialmente, propõem reagir ao modelo capitalista, preocupadas com os impactos sociais e naturais causados pela realidade vigente. Entretanto, essas idéias foram incorporadas pelo próprio sistema, condicionando os Estados e as instituições internacionais a elaborar estratégias que não alterem as "regras principais do jogo", mas que disfarcem os problemas, justificando a permanência do mesmo modelo e configurando uma nova fase do desenvolvimento capitalista. 
Como exemplo dessa situação, podemos destacar, em 1972, em Estocolmo (Suécia), a realização da Primeira Conferência Mundial de Desenvolvimento e Meio Ambiente, que visou a estimular os governos nacionais a criarem "políticas ambientais” que evitassem a degradação ambiental e restaurassem padrões de qualidade da água, do solo e do ar. Naquela conferência, em conformidade com Novaes (2003), chegou-se à conclusão de que era preciso redefinir o próprio conceito de desenvolvimento, tantas e tão complexas eram as questões envolvidas. O compromisso dessa revisão conceitual ficou a cargo de uma comissão liderada pela primeira-ministra da Noruega, Gro Brundtland, que produziu o relatório chamado "Nosso Futuro Comum", em 1987. O documento consolidou, definitivamente, o conceito de desenvolvimento sustentável como aquele que atende as necessidades do presente sem comprometer as gerações futuras. Com base nesse documento, em 1992, foi realizada a Segunda Conferência das Nações Unidas sobre Meio Ambiente, no Rio de Janeiro, conhecida como ECO 92. No evento, foi estabelecida a Agenda $21^{1}$, reconhecida como documento base a ser aplicado em todos os países do mundo visando às resoluções, principalmente, de ordem ecológica.

Essas ações, mesmo destacando questões sociais, como é o caso da pobreza e das desigualdades entre os países, salientam com maior ênfase e de forma fragmentada os problemas de ordem ecológica. Suas preocupações maiores envolvem a natureza, no que tange a sua função produtiva, em sua condição de recurso e, além disso, valorizam, de forma menos significativa, as diversidades culturais. Servem como "receitas" a ser aplicadas de forma homogênea, que visam a administrar os impactos da produção capitalista sobre a natureza. A postura política adotada por essas ações desvia o foco para as questões naturais (ambientais), afastando a necessidade de transformações estruturais, as quais são as condicionantes da degradação ambiental em todas as suas dimensões.

A sustentabilidade, propagada pelas instituições internacionais, através dos acordos citados, está, na realidade, comprometida e associada com a manutenção do modelo econômico vigente e o desenvolvimento das forças produtivas capitalistas. Essa

\footnotetext{
${ }^{1}$ A Agenda 21 é um plano de ação para ser adotado global, nacional e localmente, por organizações do sistema das Nações Unidas, governos e pela sociedade civil, em todas as áreas em que a ação humana impacta o meio ambiente. Constam, nesse documento, um conjunto de ações, propostas, programas, princípios e estratégias que se referem aos padrões de produção e consumo.
} 
concepção, que vem sendo aceita com tranquilidade pelo senso comum e que tem sido adotada pelas políticas públicas, está fundamentada no argumento de ambientalistas que defendem a necessidade da criação de um novo setor, no qual se produza tecnologia que evite problemas ambientais e corrija os impactos já produzidos.

Contudo, de acordo com Ruscheinsky (2004), sustentabilidade consiste em um conceito que admite variações em conformidade com os interesses e os posicionamentos e, por ser recente, está ainda mais sujeito a ambiguidades e dilemas quanto ao seu uso e ao seu significado. Segundo o autor, entre os cientistas e os formuladores de políticas públicas, tal conceito costuma ser sinônimo de controvérsia, porém, em meio às divergências do debate, Ruscheinsky (2004) esclarece que:

[...] as ações sustentáveis deveriam ser todas as medidas que visam manter a capacidade de reposição de uma população de uma determinada espécie animal ou vegetal. Do ponto de vista ideal, seria a sustentação da biodiversidade sem perdas ou o funcionamento de um ecossistema idêntico por longo prazo. Quando entra algum tipo de extrativismo ou exploração de recursos naturais, a sustentabilidade é a medida do que, a longo prazo, pode ser extraído ou explorado sem depauperamento do patrimônio natural. Nessa compreensão, a sustentabilidade é eminentemente uma tarefa reservada à intervenção humana. (RUSCHEINSKY, 2004 p.17)

Nesse sentido, no campo das Ciências Sociais, em consonância com Ruscheinsky (2004), em relação à sustentabilidade, existem aqueles que privilegiam as questões culturais, embasadas na difusão de um ideário e nas mudanças de valores e de comportamento. De outro lado, há os que compreendem que a sociedade sustentável, através das ações coletivas, venha a enfrentar as desigualdades sociais através de alterações que permitiriam nova forma de organização da sociedade. Todavia, existe a certeza de que é necessário modificar radicalmente o estilo moderno e ocidental de consumo.

\begin{abstract}
O desenvolvimento sustentável é um projeto social e político que aponta para o ordenamento ecológico e a descentralização territorial da produção, assim como para a diversificação dos tipos de desenvolvimento e dos modos de vida das populações que habitam o planeta. Nesse sentido, oferece novos princípios aos processos de democratização da sociedade que induzem a participação direta das comunidades na apropriação e transformação de seus recursos ambientais. (LEFF, 2002, p. 57)
\end{abstract}

Fundamentadas nessa perspectiva, surgem experiências alternativas que pretendem promover um novo desenvolvimento. Para o espaço rural, especificamente, tem se destacado a proposta agroecológica que vem fortalecendo-se, como um novo paradigma. 


\section{Desenvolvimento rural sustentável: um olhar sobre a agroecologia}

$\mathrm{Na}$ perspectiva de fomentar uma alternativa de desenvolvimento para o meio rural, a agroecologia surge comprometida com as questões naturais da produção agrícola, porém, além disso, incorpora preocupações sociais e políticas, fundamentais para a vida humana. Em conformidade com Sevilla Guzmán e Casado (1997), a agroecologia fundamenta-se na ecologia, respeitando as leis e as potencialidades dos ecossistemas naturais. No entanto, ela diferencia-se de outros tipos de agricultura ecológica, uma vez que considera inseparáveis os sistemas sociais dos ecológicos.

A agroecologia é um dos pilares do paradigma ecológico, o qual enseja novas ideias para se pensar o desenvolvimento. De acordo com Gomes (2003), esse paradigma busca estabelecer, com maior intensidade e respeitabilidade, a relação entre os saberes populares e científicos, tendo, como base epistemológica e metodológica, o pluralismo, visando a contrapor o que é, atualmente, considerado dominante. Nesse sentido, tem como diretrizes superar o preconceito existente entre as ciências naturais e exatas; o postulado da especialização como única forma de gerar o desenvolvimento; a aplicação rigorosa do método como garantia de êxito da atividade cientifica; os cientificismos; a falsa neutralidade e o autoritarismo de concepções hegemônicas.

Leff (2001) destaca que as práticas agroecológicas remetem-nos à recuperações dos saberes tradicionais. Além disso, introjetam princípios de equidade na produção, de maneira que as suas práticas permitam um acesso igualitário aos meios de vida. Para Leff (2001), é a fusão entre a “Empiria Camponesa” e a “Teoria Agroecológica” que estabelece o Desenvolvimento Rural Sustentável.

Outro princípio importante da agroecologia, que visa a promover o desenvolvimento de forma sustentável, é a valorização do empoderamento local e coletivo das comunidades, através da autogestão. Segundo Leff (2001, p. 48),

\footnotetext{
[...] novas economias endógenas e autogestionárias se fundem em uma demanda por democracia participativa e direta, que implica o seu direito de pensar, propor e realizar outros futuros possíveis, de gerar novas técnicas e de apropriar-se delas como força produtiva e de democratizar os processos de produção de seus meios de vida.
}

Assim sendo, para Sevilla Guzmán e Casado (1997), a agroecologia pretende ser um elemento de desenvolvimento endógeno da comunidade rural que compreende a produção, a tecnologia e a comercialização. É importante salientar que a comercialização justa, tanto para o consumidor, quanto para o camponês, é 
fundamental, principalmente pelo comprometimento com a segurança alimentar dos povos.

O novo paradigma agroecológico está associado a questões políticas, culturais, socioeconômicas e naturais e fundamenta-se na produção familiar camponesa, pois considera que os

[...] agricultores familiares afiguram-se como protagonistas importantes da transição à economia sustentável, já que, ao mesmo tempo em eu são produtores de alimentos e outros produtos agrícolas, desempenham a função de guardiões da paisagem e conservadores da biodiversidade. A agricultura familiar constitui, assim, a melhor forma de ocupação do território, respondendo a critérios sociais (geração de auto-emprego) a ambientais. (SACHS, 2004, p. 368).

Necessário se faz ressaltar que a agroecologia, por si só, não resolve questões estruturais da organização social atual, alicerçada no modelo capitalista de produção. Algumas experiências agroecológicas são significativas estratégias de enfrentamento ao modelo hegemônico de produção e do pensamento agronômico, todavia, os princípios promovidos pelo paradigma não serão plenos, enquanto o trabalho e a natureza permanecerem tratados como mercadoria.

Mesmo que, em comunidades, essas práticas solidárias de produção venham sendo praticadas, o desenvolvimento rural sustentável não está separado do desenvolvimento das cidades, onde se concentra o poder industrial, no qual as forças do capital são ainda mais intensas.

Na atualidade, a agroecologia é um meio, como um movimento social, que divulga formas alternativas de conceber o desenvolvimento, de forma sustentável, fundamentando-se em novas ideias e novos ideais. As políticas públicas, no Brasil, por exemplo, têm adotado princípios desse paradigma. No entanto, a maior parte da intervenção estatal ainda é direcionada aos setores conservadores, econômico e politicamente dominantes. Além disso, entre as ações do Estado e as suas variadas escalas existem diferentes concepções de desenvolvimento sustentável sendo aplicadas, gerando equívocos no direcionamento das políticas públicas.

\section{Políticas públicas e sustentabilidade rural no Brasil}

No Brasil, na última década, também por influência de preocupações internacionais, surgiram políticas públicas, organizações não governamentais, conselhos, grupos de estudos e instituições destinadas a pensar, planejar e promover o 
desenvolvimento comprometido com a sustentabilidade. Nesse aspecto, no espaço rural, podemos destacar a criação, em 1999, do Ministério de Desenvolvimento Agrário (MDA), o qual reuniu, em sua estrutura, a política de reforma agrária e o PRONAF (Programa Nacional de Fortalecimento da Agricultura Familiar), que, antes, fazia parte das atribuições do Ministério da Agricultura.

Associadas ao Ministério de Desenvolvimento Agrário (MDA) e a outros ministérios, também são estabelecidas secretarias com a função de traçar novas estratégias para enfrentar os problemas vivenciados no campo brasileiro. Entre elas, cabe ressaltar a Secretara de Desenvolvimento Territorial, a Secretaria da Agricultura Familiar, a Secretaria Nacional de Economia Solidária ${ }^{2}$ e a Secretaria de Reordenamento Agrário. Segundo o MDA, (2010), essas secretarias têm como missão consolidar o conjunto da agricultura familiar de modo a desenvolver os territórios de forma sutentável, por meio da valorização humana e da política, considerando os desejos e os anseios das organizações sociais, praticando os princípios da descentralização, da democracia e da participação social. Nessa perpectiva, começam a ser incentivadas iniciativas agroecológicas, principalmente, visando a atingir os princípios ecologicos de autogestão e comercialização promovidos pelo paradgima agroecológico.

No caso das políticas públicas, as pressões e a participação dos movimentos sociais são relevantes na efetivação de ações estatais que seguem nesse sentido. Em 1999, foi criado o Conselho Nacional de Desenvolvimento Rural Sustentável $\left(\mathrm{CONDRS}^{3}\right)$, “um espaço colegiado de proposição de diretrizes para a formulação e a implementação de políticas públicas, através da concertação e articulação entre diferentes níveis dos poderes públicos e organizações da sociedade civil”. (MDA, 2010). Esse conselho, em 2002, foi responsável por elaborar o primeiro Plano Nacional de Desenvolvimento Rural Sustentável, que plano apresentou diretrizes iniciais que pretendiam, principalmente, inserir, no mercado, os agricultores familiares, estabelecendo um novo padrão de desenvolvimento que exige, portanto:

[...] que a geração de empregos e a distribuição mais eqüitativa da renda esteja baseada em parâmetros tecnológicos e institucionais capazes de valorizar e preservar os recursos naturais, os ecossistemas e o meio

\footnotetext{
${ }^{2}$ A Secretaria Nacional de Economia Solidária é de responsabilidade do Ministério do Trabalho, no entanto, a função da mesma é importante instrumento do desenvolvimento rural sustentável.

${ }^{3}$ Órgão Colegiado do Ministério de Desenvolvimento Agrário (MDA).
} 
ambiente em geral. A atual vulnerabilidade da economia nacional aos fluxos internacionais de capital financeiro não pode ser vista como uma fatalidade irreversível. Deve ser entendida como um desafio a ser superado na busca de uma participação soberana do país em processos multilaterais e solidários de globalização. (PLANO DE DESENVOLVIMETO RURAL SUSTENTÀVEL, 2002)

A concepção anteriormente referida faz parte do entendimento de que a sustentabilidade do meio rural não depende de grandes transformações, ou seja, pode ser mediada através da criação de mecanismos que superem as dificuldades de inserção no modelo global de produção e, assim, amenizem a pobreza e os impactos na natureza.

Basicamente, o plano em questão estruturou-se em quatro programas: a) Democratização do Acesso a Terra, através da desapropriação por interesse social, arrecadação de terras públicas, vagas em assentamentos já criados, aquisição por compra de áreas produtivas e das ações do Banco da Terra, Projeto Casulo e Crédito Fundiário. b) Fortalecimento da Agricultura Familiar, por meio do crédito, do acesso à infra-estrutura, da integração entre municípios e estados, da assistência técnica, da extensão rural, da capacitação e da pesquisa e da comercialização. c) Educação Rural que deve ter como fio condutor as diretrizes e a legislação gerais da educação, considerando as diferentes regiões e as distintas realidades do país, contextualizando o ensino às realidades e às necessidades locais; envolvendo e articulando a educação da família e da comunidade em parceria com a escola formal e d) por fim, a diversificação das economias rurais, que têm como objetivo estimular a incorporação de atividades terciárias e secundárias no seio da produção da unidade familiar.

Em 2003, com a mudança de governo, o Conselho Nacional de Desenvolvimento Rural Sustentável passou a chamar-se CONDRAF. [...], “cuja sigla faz referência ao Desenvolvimento Rural, à Reforma Agrária e à Agricultura Familiar”. (Ministério de Desenvolvimento Agrário - MDA, 2010). Assim como na primeira fase do conselho, o Núcleo de Estudos Agrários e Desenvolvimento (NEAD) do Ministério de Desenvolvimento Agrário (MDA), que auxiliou na elaboração do primeiro plano, continuou subsidiando as ações do conselho composto permanentemente por secretarias do Ministério do Desenvolvimento Agrário (Secretarias de Reordenamento Agrário, de Agricultura Familiar e de Desenvolvimento Territorial) e o presidente do Instituto Nacional de Colonização e Reforma Agrária. 
A partir das diretrizes fundamentadas pelo CONDRAF, em 2005, foi publicado o Plano Territorial de Desenvolvimento Rural Sustentável. O principal diferencial desse plano em relação ao primeiro é a ênfase na abordagem territorial adotada como conceito teórico-metodológico. De acordo com o Ministério de Desenvolvimento Agrário (MDA) e Secretaria de Desenvolvimento Territorial (SDT) (2005), essa

[...] nova visão de planejamento do desenvolvimento rural voltada para o território, deriva da necessidade de articulação das políticas públicas, da formação de parcerias, de forma a viabilizar o alcance de objetivos maiores das políticas públicas para o meio rural, potencializando resultados e reduzindo desperdícios vinculados à superposição e à dispersão de esforços. (PLANO TERRITORIAL DE DESENVOLVIMENTO RURAL SUSTENTÁVEL - Ministério de Desenvolvimento Agrário - MDA, 2005, p. 09)

Nesse sentido, o planejamento territorial ajuda a aproximar as políticas públicas dos poderes locais, respeitando as especificidades culturais e demandas, assim como valorizando as dimensões socioculturais, econômica, político-institucional e ambiental. Dessa forma, os alcances dos objetivos propostos para o desenvolvimento territorial constituem-se a partir do: a) fortalecimento das redes sociais de cooperação; b) dinamização econômica nos territórios; c) articulação de políticas públicas; e d) fortalecimento da gestão social. De acordo com o diagnóstico de cada território que envolve a configuração espacial, os aspectos históricos, geoambientais, a população, a organização social, a estrutura agrária, os aspectos econômicos, os serviços sociais e o apoio à produção, à infra-estrutura social e produtiva e à cultura e ao lazer.

Portanto, entre esses planos de desenvolvimento sustentável implementados no Brasil, podemos perceber diferenças e avanços. O primeiro plano destaca as problemáticas vivenciadas no campo e tem foco econômico, ademais, reconhece a importância da agricultura familiar no processo de desenvolvimento da economia do país, no entanto apresenta-se mais comprometido com questões internacionais do mercado. A concepção de educação rural, por exemplo, destacada pelo plano de 2002, pressupõe preparar os jovens para integrar os desafios da modernidade e da tecnologia, absorvendo-os sem contestação da forma desigual na qual eles expressam-se, assumindo, muitas vezes, valores estrangeiros e desvalorizando saberes, quer locais, quer populares. A educação rural aparece, neste caso, como instrumento de qualificação e adaptação da mão de obra para mercado. 
Ambos os planos consideram central a importância do agricultor familiar e a necessidade de sua inserção diferenciada no mercado global. No entanto, apresentam abordagens diferenciadas ao tratar as políticas públicas e a sua articulação com os territórios. O plano territorial de desenvolvimento rural sustentável (2005) visa a reduzir as desigualdades sociais e gerar riquezas com equidade social, através do protagonismo das comunidades, do empoderamento local e da autogestão. Nesse plano, não são traçadas políticas gerais que devem ser aplicadas em todo território nacional, mas perspectivas que devem subsidiar o planejamento dos territórios.

Em face destas proposições, para auxiliar a formulação de diretrizes para os territórios e estimular a participação popular foi organizada a Conferência de Desenvolvimento Nacional Rural Sustentável e Solidário realizada em 2008. Essa conferência foi valiosa oportunidade de avaliar a efetividade das diretrizes anteriores e debater perspectivas, tendo contado com 1.556 participantes, sendo 1.207 delegados (as) estaduais e nacionais, 234 convidados (as) e 115 observadores. Agricultores (as), assentados(as), camponeses(as), comunidades quilombolas, jovens, povos indígenas, agroextrativistas, pescadores(as) artesanais, representantes de empreendimentos cooperativos e da economia solidária, comerciantes, industriais, agentes de saúde e professores(as) e gestores públicos participaram da referida Conferência.

Com o objetivo de formular a Política Nacional de Desenvolvimento Sustentável e Solidário do Meio Rural que contemplasse as diversidades sociais e regionais do país, essa Conferência configurou-se numa forma mais ampla do que somente o conselho para pensar o desenvolvimento sustentável do território nacional.

Ressalve-se, contudo, que, mesmo considerando os avanços trazidos pelo debate dos planos e a sua preocupação com a sustentabilidade entre os povos e na relação com o meio ambiente, não há previsão de alterações estruturais da sociedade. A própria Reforma Agrária, destacada nos planos, é um exemplo disso, não enfrenta de forma efetiva a concentração fundiária, pois não limita o tamanho das propriedades e está fundamentalmente baseada na desapropriação através da compra de terras pelo Estado.

Outro elemento, que demonstra o limite das intenções expressas nas políticas brasileiras é a tolerância paralela à existência de distintos projetos de desenvolvimento produzidos com o auxílio de outros órgãos, instituições e até empresas que, no âmbito do Estado, são incorporados pelo Ministério da Agricultura, Pecuária e Abastecimento 
(MAPA). Um exemplo dessa contradição pode verificar-se na publicação do Plano Agrícola e Pecuário: Agricultura é Sustentabilidade e Crescimento (2010 - 2011).

Para esse plano, estimular o desenvolvimento sustentável da agropecuária consiste em incentivar especialmente a agricultura de "baixo carbono”. Essa concepção do desenvolvimento rural e da sustentabilidade simplifica a questão à ideia de crescimento agroeconômico e de preservação natural. Além disso, o Ministério da Agricultura, Pecuária e Abastecimento (MAPA) tem como foco central subsidiar o crescimento da agricultura empresarial, que está fundamentada na média e na grande propriedade, na exportação e na monocultura e gera, consequentemente, a concentração de renda e a desigualdade. “As políticas agrícolas que mais impactaram pelos resultados imediatos e em médio prazo, com evidentes repercussões de mais amplitude em alguns casos, como da cana-de-açúcar, estiveram vinculadas aos produtos de exportação”. (THOMAZ JR, 2010, p. 185).

Portanto, vê-se que o campo de atuação do Estado é tenso e constantemente paradoxal, pois é medido pelos embates travados na própria sociedade, na qual aqueles que estiverem melhor representados assumem o protagonismo da política. Atualmente, no Brasil, podemos destacar, no âmbito do espaço rural, duas posições que representam essas contradições e as disputas internas no bloco de poder do Estado. Uma está representada pelo Ministério da Agricultura, Pecuária e Abastecimento (MAPA), o qual destina as suas ações, principalmente, ao agronegócio e é constituído pelos setores mais conservadores ligado aos ruralistas. E outra é representada pelo Ministério de Desenvolvimento Agrário (MDA) que volta suas ações, essencialmente, à agricultura familiar e à Reforma Agrária, sendo composto, até mesmo, por membros indicados pelos movimentos sociais.

A convivência dessas estruturas produtivas no Brasil, de um lado, os monocultivos, grandes extensões de terra, as commodities, vinculadas aos conglomerados agroquímico - alimentar - financeiros e todo o aporte público (logística, infraestrutura), e, de outro, a estrutura familiar camponesa, apesar das dificuldades, conta com o apoio de financiamento público, produto de muita luta e enfrentamentos políticos nas diversas escalas geográficas. No entanto, fragiliza-se devido à ausência de políticas duradouras para aumentar o efeito das áreas de alimentos e envolver mais famílias na produção, via reforma agrária, ou mesmo que fosse a enganosa política de assentamentos. Não estamos diante de um exemplo a ser seguido, pois as melhores terras - mais férteis, mais planas, com condições hídricas diferenciadas e acesso à logística de transportes - estão se concentrando cada vez mais nas mãos dos grandes produtores de commodities, tais como a soja, o milho, a cana-de-açúcar. (THOMAZ JR, 2010, p. 196). 
Nesse contexto, o Estado, apesar da aparente neutralidade, atende os interesses da elite agrária e fundiária, ao mesmo tempo em que procura prestigiar os interesses conflitantes através de políticas compensatórias. Os interesses que contrapõem capital, trabalho “rendem”-se no plano ideológico do Estado através da sua aparente neutralidade. No entanto, ela

\begin{abstract}
[...] é uma ficção ao gosto das classes dominantes, porque a apropriação desigual da riqueza requer o mínimo de consenso e esse se constrói no plano ideológico, transformando conveniências de classe em verdade para toda a sociedade. É por isso que associar o Estado à busca do bem comum é ignorar sua profunda vinculação com os interesses hegemônicos de um dado momento histórico, em torno dos quais emergem projetos de gestão pública que não são meramente econômicos, mas sim territoriais, porque impõem determinadas correlações de forças que darão o tom das assimetrias. (PAULINO, 2010, p. 119).
\end{abstract}

O caráter de universalidade que o Estado tem buscado favorecer, segundo Mazzetto Silva (2004), não pode se realizar na modernidade capitalista, porque "há de se entender que o desenvolvimento capitalista é por si mesmo contraditório: cria e destrói; gera riqueza de um lado e miséria de outro”. (SILVA, 1998, p. 60). Para não se destruírem, os oponentes necessitam de um poder regulador, o Estado, que, no entanto, não esteja acima das classes, mas que possa ser apropriado pelos mais poderosos.

Por isso, sobretudo a construção de um novo modelo agrário/ rural, que possa desenvolver-se na diversidade, com sustentabilidade e democracia participativa, requer fundamentalmente reelaborar o Estado (MAZZETTO SILVA, 2004).

\title{
Considerações Finais
}

A questão do desenvolvimento é forma hegemônica associada ao crescimento econômico e ao fortalecimento das forças produtivas capitalistas. Esse modelo de pensamento trouxe fortes impactos à sociedade e à natureza, o que provocou reações na busca por alternativas e, em virtude disso, emergiu o debate sobre o desenvolvimento sustentável. Porém, esse debate foi cooptado pelas forças do capital como fórmula de renovar-se. Dessa maneira, o debate da sustentabilidade incorpora-se ao senso comum como política restrita às questões naturais, alijando a discussão das relações sociais desiguais e a exploração, que são as principais motivadoras da insustentabilidade.

Entretanto, nesse mesmo contexto, a sustentabilidade rural proposta pelos defensores do paradigma agroecológico tem se destacado como movimento estratégico que produz alternativas, as quais se contrapõem ao modelo hegemônico do capital. 
Diversas experiências agroecológicas vêm subsidiando a elaboração e a implantação de políticas públicas que incorporam, no discurso, a preocupação com o desenvolvimento rural sustentável.

No Brasil, podemos salientar, na última década, a criação de dois planos de desenvolvimento rural sustentável que introduzem importantes princípios agroecológicos e sustentáveis, além do estabelecimento de secretarias, conferências e instituições comprometidas com essa abordagem. Notam-se avanços, em especial, quanto à questão ambiental, a importância da participação coletiva e as diferentes dimensões da sociedade como a cultura, a economia e a política. Também se reconhece, com maior ênfase, a relevância da agricultura familiar, a distribuição equitativa da riqueza e a superação das desigualdades sociais. No entanto, as mudanças previstas nas políticas analisadas não enfrentam as reais estruturas da organização social, mantendose as contradições, o que ainda as impedem de conquistar a sustentabilidade.

\section{Referências}

BRASIL. Ministério da Agricultura, Pecuária e Abastecimento. Disponível em: $<$ http// www.mapa.gov.br>. Acesso em: Julho de 2010.

BRASIL. Ministério de Desenvolvimiento Agrário. Disponível em: <http// www.mda.gov.br>. Acesso em: Julho de 2010.

BRASIL. Ministério de Desenvolvimiento Agrário. Plano Nacional de Desenvolvimento Rural Sustentável. Brasília, DF, 2005.

BRASIL. Ministério de Desenvolvimiento Agrário. Plano Territorial de Desenvolvimento Rural Sustentável. Brasília, DF, 2005.

ESTEVA, G. Desenvolvimento. SACHS, W. (Org.). Dicionário do desenvolvimento: guia para o conhecimento como poder. Tradução Joscelyne, V. L. M; Gyalokay, S. e Clasen, J. A. Petrópolis: Vozes, 2000. 69 - 83p.

GOMES, J. C. C. Pluralismo Epistemológico e Metodológico como base para o Paradigma Ecológico. Revista Ciência e Ambiente n 27: Agricultura Sustentável. Santa Maria: Universidade Federal de Santa Maria. Julho/Dezembro, 2003.

LEFF, H. Saber ambiental: sustentabilidade racionalidade, complexidade, poder. 2. ed. Rio de Janeiro: Vozes, 2002.

LEFF, H. Agroecologia e saber ambiental. Revista Agroecologia e Desenvolvimento Rural Sustentável. Porto Alegre, v.3, n.1, p. 36 - 51. jan./mar, 2002. 
MAZZETTO SILVA, C. E. Políticas Públicas e Desenvolvimento Rural: em busca de novos caminhos. In: OLIVEIRA, U. A. e MARQUES, M. I. M. O campo no século XXI: Território de vida, de luta e de construção da justiça social. São Paulo: Paz e Terra e Casa Amarela, 2004. 335 - 352p.

NOVAES, W. Agenda 21: um novo modelo de civilização. In TRIGUEIRO, C. Meio Ambiente no Século 21. Rio de Janeiro: Sextante, 2003, 323-331p.

PAULINO, E. T. Políticas territoriais e Questão Agrária: da teoria a intervenção. In: SAQUET, M. A. e SANTOS, R. A. (Org) Geografia agrária, território e desenvolvimento. São Paulo: Expressão Popular, 2010. 107-130p.

RUSCHEINSKY, A. No conflito das interpretações: o enredo da sustentabilidade. In RUSCHEINSKY, A (Org). Sustentabilidade: uma paixão em movimento. Porto Alegre: Editora Meridional, 2004. 15 - 33p.

SACHS, I. Brasil rural: da redescoberta à invenção. In: OLIVEIRA, U. A. \& MARQUES, M. I. M. O campo no século XXI: Território de vida, de luta e de construção da justiça social. São Paulo: Paz e Terra e Casa Amarela, 2004. 365 - 372p.

SEVILLA GUZMÁN, E. A perspectiva sociológica em Agroecologia: uma sistematização de seus métodos e técnicas. Revista Agroecologia e Desenvolvimento Rural Sustentável. Porto Alegre, v.3, n.1, p. 18 - 28. jan./mar, 2002.

SILVA, J. G. A nova dinâmica da agricultura brasileira. 2. ed. Campinas: Unicamp, 1998. 217p.

SEVILLA GUZMÁN e CASADO, G.I.(Org.) Estilos de agricultura ecolóxica a agroecoloxía en Andalucía. Córdoba: Ed. FOUCI, 1997.

THOMAZ JR, A. Desenvolvimento destrutivo das forças produtivas, a insustentabilidade do capital e os desafios para a produção de alimentos. In: THOMAZ JR, A. e FRANÇA JR, L. B. (Orgs.). Geografia e Trabalho no século XXI. v.5. Presidente Prudente: Centelha, 2010. 176 - 216p. 